\title{
CAPÍTULO 11: AVALIAÇÃO DA QUALIDADE DO LEITE CRU REFRIGERADO DE PROPRIEDADES LEITEIRAS DO VALE DO TAQUARI-RS
}

\author{
CAPÍTULO 11: EVALUACIÓN DE LA CALIDAD DE LA LECHE CRUDA \\ REFRIGERADA DE LAS EXPLOTACIONES LECHERAS DEL VALLE DE \\ TAQUARI-RS
}

\section{CHAPTER 11: EVALUATION OF THE QUALITY OF REFRIGERATED RAW MILK FROM MILK HOLDINGS IN THE TAQUARI VALLEY}

\author{
Jeferson Aloísio Ströher ${ }^{1}$; Thaís Benincá² ${ }^{2}$ Rosiele Lappe Padilha ${ }^{3}$; Luís Carlos Oliveira dos Santos $\mathrm{Jr}^{4}$
}

DOI: https://doi.org/10.31692/978-65-88970-18-8.150-170

\begin{abstract}
RESUMO
A qualidade do leite depende de alguns fatores ligados à produção, sendo eles: o manejo dos animais e de ordenha, higienização dos equipamentos e utensílios, a refrigeração do leite e a mão-de-obra qualificada dos ordenhadores. Por isto, entrou em vigor em 2018, as instruções normativas $n^{\circ} 76$ e 77 , que visam a produção de leite de maior qualidade no Brasil. As boas práticas agropecuárias (BPA) são um conjunto de atividades na propriedade rural, que possui objetivo de garantir a saúde, o bem-estar e a segurança dos animais, do homem e do ambiente. O objetivo deste trabalho foi verificar em 27 propriedades (após a constatação da contagem padrão em placas (CPP) acima do padrão nos meses de novembro e dezembro de 2020), as condições de higiene e propor melhorias necessárias para a qualidade do leite produzido. Foram observados através de duas visitas às propriedades, quatro itens do plano de qualificação de fornecedores de leite (PQFL) como preconiza a legislação (MAPA, 2018). Os itens avaliados foram: IV- refrigeração do leite; VI- higiene de superfícies, equipamentos e instalações; IXmanejo de ordenha e pós-ordenha; X- adequação das instalações, equipamentos e utensílios e o item XVI- adoção de práticas de manejo racional e de bem-estar animal. Podemos constatar que na primeira visita às propriedades, houve não conformidades nos itens de $n^{\circ}$ VI $(25,92 \%)$, IX (37,03\%) item X $(40,74 \%)$ e a conformidade no item XVI. Já na segunda visita mesmo tendo todos os itens das BPA conformes, ainda observou-se que 6 propriedades estavam inconformes com a CPP. Foi constatado que o uso de detergentes como o alcalino clorado, o detergente ácido, alcalino e o neutro, além de práticas como o teste de CMT, e o pré e pós-dipping são fundamentais na melhoria da qualidade do leite produzido. Na primeira visita, seis propriedades estavam com a temperatura do leite acima da legislação $\left(\leq 4,0^{\circ} \mathrm{C}\right)$ e na segunda visita duas ainda estavam com este problema. O teste da estabilidade ao alizarol foi conforme nas duas visitas às propriedades.

Palavras-Chave: qualidade do leite, instrução normativa, higienização da ordenha, contagem padrão em placas.
\end{abstract}

\section{RESUMEN}

La calidad de la leche depende de algunos factores ligados a la producción, siendo éstos: el manejo de los animales y el ordeño, la sanidad de los equipos y utensilios, la refrigeración de la leche y la mano de obra cualificada de los encargados. Para ello, entraron en vigor en 2018, las instrucciones normativas $\mathbf{n}^{\circ}$ 76 y 77, que tienen como objetivo la producción de leche de mayor calidad en Brasil. Las Buenas Prácticas Agrícolas (BPA) son un conjunto de actividades en la propiedad rural, cuyo objetivo es garantizar la salud, el bienestar y la seguridad de los animales, el hombre y el medio ambiente. El objetivo de este trabajo fue verificar en 27 propiedades (tras la comprobación del recuento de placas estándar (CPE) por encima de la norma en los meses de noviembre y diciembre de 2020), las condiciones

${ }^{1}$ Programa de Pós-Graduação em Ciência e Tecnologia de Alimentos, Universidade Estadual do Rio Grande do Sul, jeferson.stroher@hotmail.com

${ }^{2}$ Mestra em Ambiente e Sustentabilidade, Universidade Estadual do Rio Grande do Sul, thais_beninca@hotmail.com

${ }^{3}$ Doutora em Engenharia de Alimentos, Universidade Federal de Santa Maria, rosiele-lappe@uergs.edu.br

${ }^{4}$ Doutor em Engenharia de Alimentos, Universidade Federal de Santa Catarina, luisc.oliveirajr@gmail.com 
higiénicas y proponer las mejoras necesarias para la calidad de la leche producida. A través de dos visitas a las fincas se observaron cuatro puntos del plan de calificación de proveedores de leche (PQFL), tal y como recomienda la legislación (MAPA, 2018). Los ítems evaluados fueron: IV- refrigeración de la leche; VI- higiene de las superficies, equipos e instalaciones; IX- gestión del ordeño y post ordeño; Xadecuación de las instalaciones, equipos y utensilios y el ítem XVI- adopción de prácticas racionales de gestión y bienestar animal. Podemos comprobar que en la primera visita a las propiedades, hubo no conformidades en los ítems VI (25,92\%), IX (37,03\%) ítem X (40,74\%) y la conformidad en el ítem XVI. Ya en la segunda visita, incluso habiendo cumplido todos los puntos de las BPA, se observó que 6 propiedades no cumplían con el PPC. Se comprobó que el uso de detergentes como el alcalino clorado, el ácido, el alcalino y el neutro, y prácticas como la prueba CMT, y la inmersión previa y posterior son esenciales para mejorar la calidad de la leche producida. En la primera visita, seis propiedades tenían la temperatura de la leche por encima de la legislación $\left(\leq 4,0^{\circ} \mathrm{C}\right)$ y en la segunda visita dos propiedades seguían teniendo este problema. La prueba de estabilidad del alizarol se cumplió en ambas visitas a las propiedades.

Palabras Clave: calidad de la leche, instrucción normativa, higiene del ordeño, recuento de placas estándar.

\begin{abstract}
The quality of milk depends on some factors related to production, such as: the management of animals and milking, equipment and utensils sanitation, milk refrigeration and the qualified labor of the orderers. For this, came into force in 2018, the normative instructions No. 76 and 77, which aim to produce higher quality milk in Brazil. Good agricultural practices (GAP) are a set of activities in rural property, which has the objective of ensuring the health, welfare and safety of animals, man and the environment. The objective of this work was to verify in 27 properties (after the verification of the standard plate count (SPC) above the standard in the months of November and December 2020), the hygiene conditions and propose necessary improvements for the quality of the milk produced. Through two visits to the properties, four items of the milk supplier qualification plan (PQFL) were observed, as recommended by the legislation (MAPA, 2018). The items evaluated were: IV- milk refrigeration; VI- hygiene of surfaces, equipment, and facilities; IX- milking and post-milking management; X-adequacy of facilities, equipment, and utensils; and item XVI- adoption of rational management practices and animal welfare. We can see that in the first visit to the properties, there were nonconformities in items VI (25.92\%), IX $(37.03 \%)$ item X (40.74\%) and the conformity in item XVI. In the second visit, even though all items of GAP were in conformity, it was still observed that 6 properties were not in conformity with CPP. It was found that the use of detergents such as chlorinated alkaline, acid, alkaline and neutral detergent, in addition to practices such as the CMT test, and the pre and post-dipping are essential in improving the quality of milk produced. In the first visit, six properties had the milk temperature above the legislation $\left(\leq 4.0^{\circ} \mathrm{C}\right)$ and in the second visit two properties still had this problem. The alizarol stability test was compliant in both visits to the properties.
\end{abstract}

Keywords: milk quality, normative instruction, milking hygiene, standard plate count.

\title{
INTRODUÇÃO
}

O leite é um alimento rico em muitos nutrientes, como os carboidratos, gordura, sais minerais e vitaminas. Porém, devido ao seu elevado valor nutricional junto com o pH neutro e a alta atividade de água, serve como um excelente meio de crescimento para diferentes microorganismos, oriundos do manejo humano, do ambiente e dos utensílios usados na ordenha (YOON, Y.; LEE, S.; CHOI, K.CHOI et al., 2016). Segundo ANUALPEC (2016), apesar do Brasil ser um dos maiores produtores de leite do mundo, a produtividade no país ainda é baixa, sendo de apenas $1.381 \mathrm{~L} /$ vaca ordenhada/ano. 
No Brasil, o leite é um dos seis produtos mais importantes produzidos pela agropecuária

brasileira, gerando emprego e renda para a população (EMBRAPA, 2016). A produção de leite brasileira no ano de 2019, atingiu cerca de 34 bilhões de litros de leite, sendo o quarto maior produtor mundial (CEPEA, 2020; CILEITE, 2020).

O Censo Agropecuário do IBGE (Instituto Brasileiro de Geografia e Estatística) mostra que em 2017, existiam quase 600 mil produtores (51\% do total) que produziam menos de 20 litros por dia, responsáveis por um total de 1,7 bilhão de litros (6\% da produção nacional). Outros 500 mil produtores produziram entre 20 e 200 litros por dia (42\% dos produtores) e foram responsáveis por um total de 12,3 bilhões de litros (41\% da produção nacional). Esses dois grupos formados por produtores que produzem até 200 litros de leite por dia representaram 93\% do total em 2017 e contribuíram com 47\% da produção nacional (IBGE, 2017).

Segundo a FAO (Organização das Nações Unidas para a Alimentação) (2017), a falta de qualidade do leite brasileiro é reconhecida e ela traz consequências insatisfatórias nos produtos produzidos, dentre elas, a contaminação microbiológica.

Os autores Menezes et al. (2015), destacam que a falta de higiene antes, durante e o pós ordenha gera grandes prejuízos financeiros e de qualidade. Estas alterações podem ocasionar a mudança da composição do leite, a quantidade de leite produzida com redução de gordura, sólidos desengordurados, lactose e caseína, além de aumento de cloretos e de soro proteínas (SANTOS; FONSECA, 2007).

\section{FUNDAMENTAÇÃO TEÓRICA}

Para minimizar a contaminação do leite cru refrigerado, a legislação brasileira regida pelo Ministério da Agricultura Pecuária e Abastecimento (MAPA) publicou as $\mathrm{IN} \mathrm{n}^{\circ} 76$ e 77 (BRASIL, 2018). A IN 76 revogou as demais normativas e alterou os parâmetros de qualidade para a produção do leite cru refrigerado no Brasil. Na Tabela 1, podemos verificar os padrões de identidade e qualidade (PIQ) que o leite cru refrigerado deve possuir. 
Tabela 1. Padrões de identidade e qualidade (PIQ) do leite para a produção do leite cru refrigerado.

\begin{tabular}{lc}
\hline \multicolumn{1}{c}{ Parâmetro de qualidade } & Limites \\
\hline CPP (Contagem padrão em placas & $\leq 300.000 \mathrm{UFC} / \mathrm{mL}$ \\
CCS (Contagem de células somáticas) & $\leq 500.000 \mathrm{Céls} / \mathrm{mL}$ \\
Gordura & $\geq 3,0 \mathrm{~g} / 100 \mathrm{~g}$ \\
Proteína total & $\geq 2,9 \mathrm{~g} / 100 \mathrm{~g}$ \\
Lactose anidra & $\geq 4,3 \mathrm{~g} / 100 \mathrm{~g}$ \\
Sólidos não gordurosos & $\geq 8,40 \mathrm{~g} / 100 \mathrm{~g}$ \\
Sólidos totais & $\geq 11,40 \mathrm{~g} / 100 \mathrm{~g}$ \\
Acidez titulável & Entre $0,14 \mathrm{e} 0,18$ ácido lático $/ 100 \mathrm{~g}$ \\
Estabilidade ao alizarol & Estável ao alizarol $72 \% \mathrm{v} / \mathrm{v}$ \\
Densidade relativa & Entre $1,028 \mathrm{e} 1,034 \mathrm{a} 15^{\circ} \mathrm{C}$ \\
Indice crioscópico & Entre $-0,530 \mathrm{e}-0,555^{\circ} \mathrm{H}$ \\
\hline
\end{tabular}

Fonte: Adaptado (BRASIL, 2018).

Conforme Brasil (2018), o leite cru refrigerado deve apresentar médias trimestrais de Contagem Padrão em Placas (CPP) de no máximo 300x10³ UFC/mL para o tanque individual ou de uso comunitário do produtor e de $900 \times 10^{3} \mathrm{UFC} / \mathrm{mL}$ antes de ser processado no estabelecimento industrial (BRASIL, 2018). A interrupção da coleta de leite deverá ser realizada pelo estabelecimento caso a propriedade obter durante três meses consecutivos, valores de média geométrica superior ao que é permitido para a análise de CPP e o retorno da coleta de leite poderá ser efetuada posterior identificação da causa e realização de ações corretivas, além de apresentar um resultado dentro do padrão (BRASIL, 2018).

Alguns fatores ligados à produção do leite são os responsáveis pela sua baixa qualidade, como: o manejo dos animais e ordenha deficientes, higienização inadequada dos equipamentos e utensílios, falta de refrigeração e de mão de obra qualificada (VALLIN et al., 2009). Durr (2012) relatou que os principais indicadores que interferem na qualidade do leite são a CPP e a CCS (contagem de células somáticas). A CPP encontra-se relacionada com adequação do armazenamento do leite pós-ordenha, a higienização da vaca na pré-ordenha a higienização dos utensílios (tanques de resfriamento, ordenha mecânica, caminhão transportador, etc.) e a higienização do ordenhador e a CCS está relacionada a inflamação da glândula mamária do animal, que causa a mastite.

As Boas Práticas Agropecuárias (BPA) são um conjunto de atividades na propriedade rural que objetivam garantir a saúde, o bem-estar e a segurança dos animais, do homem e do ambiente. São associadas ao processamento de derivados lácteos seguros e de qualidade, à sustentabilidade ambiental e à possibilidade de agregação de valor, além de ser uma exigência dos consumidores e da legislação (EMBRAPA, 2005). A IN nº 77 (BRASIL, 2018) explana 
que a indústria de laticínios deve possuir em seu autocontrole, um plano de qualificação de fornecedores de leite (PQFL) que deve contemplar a assistência técnica e gerencial, bem como a capacitação de todos os seus fornecedores, com foco em gestão da propriedade e implementação das BPA. As BPA implementadas na execução do plano de qualificação de fornecedores de leite devem contemplar no mínimo 16 itens.

Dito isto, a higienização dos materiais antes e após a ordenha dos animais, são de grande importância na qualidade do leite. Na propriedade rural, para a higienização da ordenha e equipamentos utilizados diariamente, podem ser utilizados alguns produtos químicos, sendo eles os detergentes, sanitizantes e outros (SINDILEITE, 2020).

A dosagem inadequada dos detergentes é um dos principais problemas que está relacionado com o processo de limpeza dos equipamentos de ordenha, ocasionando redução em sua eficácia (SANTOS; FONSECA, 2019). Todos os produtos químicos adquiridos pela propriedade devem ser armazenados em local apropriado, arejado, identificado, com acesso somente às pessoas autorizadas. Produtos como agrotóxicos, antiparasitários e de limpeza devem ser acondicionados em locais separados de outros produtos químicos de uso rotineiros e sua manipulação necessita do uso obrigatório de Equipamento de Proteção Individual (EPI) (SINDILEITE, 2020).

Os sanitizantes e/ou desinfetantes são os produtos que possuem a finalidade de eliminar bactérias das superfícies dos equipamentos e utensílios após a limpeza. Os produtos chamados de sanitizantes ou desinfetantes são o hipoclorito de sódio, ácido peracético, entre outros (SINDILEITE, 2020). O uso dos detergentes são os produtos químicos que têm a finalidade de remover os resíduos do leite e outras sujidades da superfície dos equipamentos, instalações e dos ordenhadores, e são classificados como alcalinos clorados, ácidos ou neutros (SINDILEITE, 2020).

A realização da sanitização nos equipamentos de ordenha é uma prática que visa a eliminação de micro-organismos capazes de causar enfermidades, além de contribuir para diminuição da contaminação do leite devido à redução de agentes contaminantes (REDIN; MACHADO, 2016). A contaminação do leite pode ser reduzida com a realização da desinfecção dos equipamentos antes do início da ordenha, sendo esta prática importante na eliminação dos micro-organismos capazes de sobreviver ao processo de limpeza ou aqueles que conseguem se multiplicar no período entre as ordenhas (SANTOS; FONSECA, 2019). Segundo Santos e Fonseca (2019), os produtos mais utilizados para esse processo são os compostos à base de cloro, no qual apresentam amplo espectro de ação. Para a sanitização do 
equipamento, pode ser empregado no processo solução com 200ppm de cloro, sendo necessário ter cuidado com resíduos do produto (ZAFALON et al., 2008).

Segundo o Sindileite (2020), alguns cuidados são necessários para que metas sejam alcançadas, como a condução das vacas para a ordenha de forma organizada, sem agitação ou barulho; fazer uma linha de ordenha; garantia que os tetos estejam limpos e secos no momento da ordenha, não molhar o úbere; retirar os três primeiros jatos de leite de cada teto em uma caneca de fundo preto e observar o seu aspecto e separar e descartar o leite dessa vaca; desinfetar os tetos antes da ordenha (pré-dipping); deixar o produto agir pelo tempo recomendado pelo fabricante (20 a 30 segundos).

O tempo decorrido entre a retirada dos primeiros jatos na caneca de fundo preto e a colocação das teteiras não deve ultrapassar 1 minuto e 30 segundos. Dessa forma há uma melhor descida do leite e evita os casos de sobre ordenha, que prejudicam a saúde do úbere. Deve-se manter a vaca em pé após a ordenha (por no mínimo 30 minutos), a fim de evitar a contaminação bacteriana do canal do teto e a realização do teste CMT - Califórnia Mastitis Test (teste da raquete) pelo menos uma vez por mês (SINDILEITE, 2020).

O equipamento de ordenha é considerado como uma fonte de contaminação do leite (GUERREIRO et al., 2005). O objetivo da realização do processo de limpeza dos equipamentos de ordenha é para que seja feita a remoção tanto de componentes orgânicos como os minerais do leite que permanecem no interior dos equipamentos, prática realizada posterior o término da ordenha (SANTOS; FONSECA, 2019).

Segundo Santos e Fonseca (2019), os resíduos orgânicos do leite são formados por componentes como proteína, gordura e lactose. A umidade, temperatura e o tempo em que permanecem em contato são alguns dos fatores que contribuem para que ocorra a fixação desses componentes nas tubulações. Diante disso, iniciar o processo de limpeza logo após a ordenha ter acabado, é fundamental, pois as tubulações estão em temperatura morna e desta forma a limpeza é facilitada, pois ainda não ocorreu a formação de depósito dos resíduos (VIDAL; NETTO, 2018).

São quatro etapas recomendadas durante o processo de limpeza dos equipamentos, onde incialmente deve ser realizado um pré-enxague apenas com água, posteriormente a utilização de detergente alcalino clorado, uso de detergente ácido e antes de iniciar a próxima ordenha do dia deve ser feita a desinfecção dos mesmos (SANTOS; FONSECA, 2019).

Mesmo com a variação existente nos equipamentos de ordenha sobre seu modelo e configuração, quando se refere aos sistemas de leite canalizado é realizado a limpeza por circulação sendo esta do tipo "Clean in place” (CIP), onde as soluções de limpeza utilizadas 
circulam, iniciando esse processo no tanque de limpeza e passando por demais componentes que possuem contato com o leite. O tempo em que a solução de limpeza permanece em contato com as superfícies deve ser suficiente para que se obtenha sua ação química e física (SANTOS; FONSECA, 2019).

A eficiência da limpeza dos equipamentos de ordenha pode ser avaliada por meio das características da água e sanitizantes, assim como a realização da inspeção visual dos mesmos e a utilização de métodos de contagem de micro-organismos.

Quanto a higienização dos equipamentos de ordenha, devem seguir as recomendações de cada fabricante dos equipamentos. As adaptações e as improvisações comprometem o funcionamento do equipamento e causam prejuízos, interferindo negativamente na qualidade e na quantidade de leite. Alguns dos equipamentos que são utilizados na ordenha são citados a seguir: balde semifechado, coador telado, caneca telada ou de fundo preto (Figura 1), placa e reagente de CMT, tarros/latões, aplicador de desinfetante (pré e pós-dipping) (SINDILEITE, 2020).

Figura 1. Teste da caneca preta (A), e resultado do teste da caneca preta (B), onde se pode verificar a presença de grupos na retirada dos três primeiros jatos de leite. Já a imagem (C) mostra a adição de pós-dipping após a ordenha e a imagem (D) a secagem dos tetos com papel toalha individual.
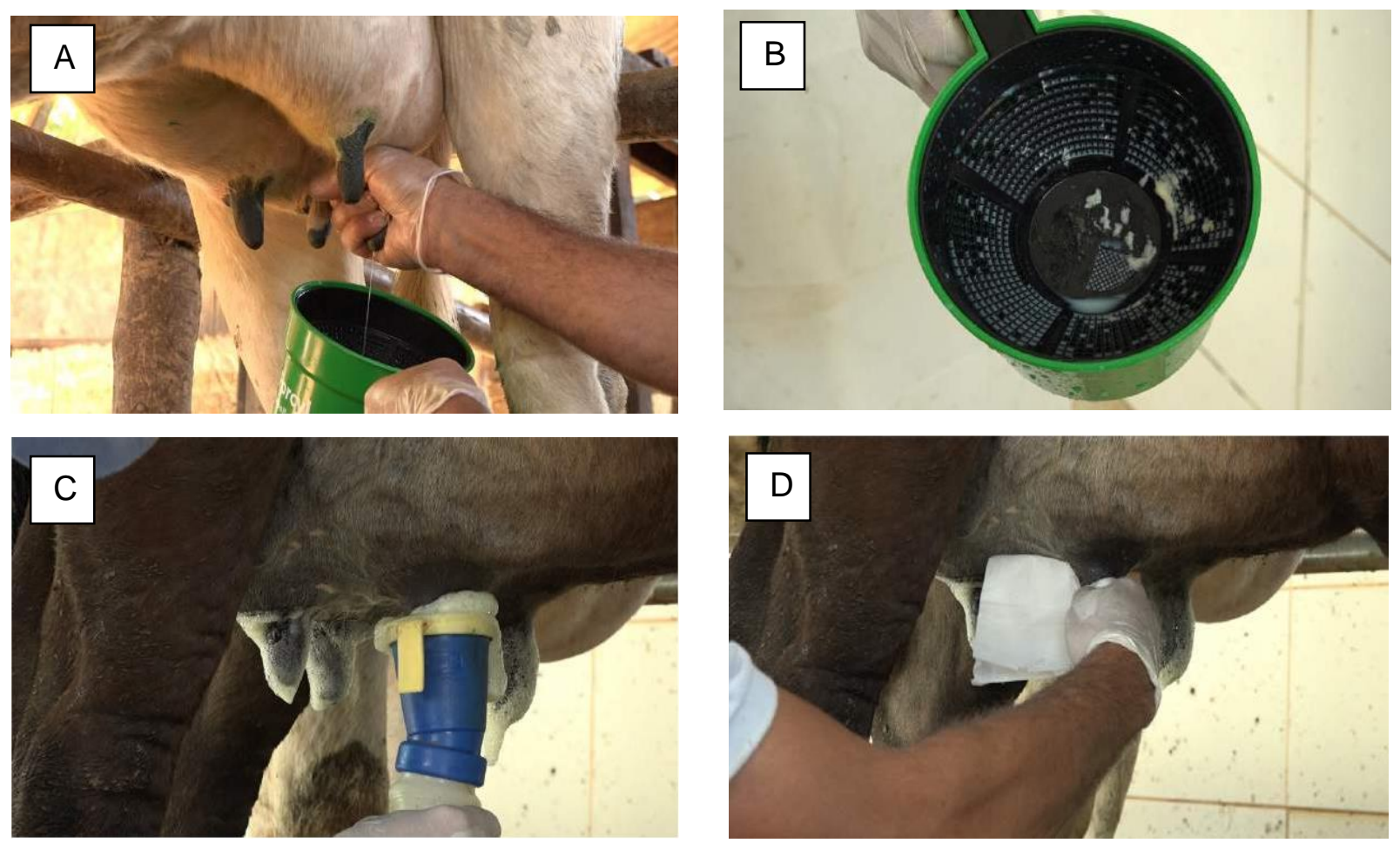

Fonte: Cotta et al., (2020).

Levando em consideração que o equipamento de ordenha possa servir para o leite como uma fonte de contaminação e que os procedimentos utilizados durante a higienização dos mesmos apresentam grande influência sobre o índice de contaminação bacteriológica, é 
fundamental orientar o produtor para a formação de um pensamento crítico sobre a aplicação

de práticas de manejo, desta forma contribuindo para obtenção de leite com extrema qualidade bacteriológica (CAVALCANTI et al., 2010). A higienização do resfriador tipo expansão também deverá passar por um protocolo pré-estabelecido de higienização, conforme cada fabricante de produtos químicos.

Quanto a alguns cuidados dos equipamentos de ordenha que são importantes para manter a qualidade do leite, podemos citar as mangueiras, sendo que quando são utilizadas por longos períodos e sem a troca regular dos mesmos, acaba apresentando rachaduras e fissuras sendo este um local ideal para que ocorra o acúmulo de resíduos de leite, contribuindo desta forma para a multiplicação microbiana (SANTOS; FONSECA, 2019).

Desta forma, este trabalho possui o objetivo de avaliar as boas práticas agropecuárias adotadas nas propriedades rurais quanto alguns itens do capítulo III do Plano de Qualificação de Fornecedores de Leite (BRASIL, 2018).

\section{METODOLOGIA}

A pesquisa exploratória, de cunho qualitativo, utilizou como instrumento a coleta de dados empregando um questionário impresso, estruturado com 30 questões objetivas e subjetivas em 27 propriedades selecionadas situadas em cinco municípios do Vale do TaquariRS. Para a seleção das propriedades, foram observadas as análises de CPP inconformes durante os meses de novembro e dezembro de 2020 de um grupo de 42 produtores. No mês de dezembro houve uma visita às propriedades para o apontamento e verificação das avarias quanto os itens abaixo, que fazem parte dos dezesseis itens do Plano de qualificação dos fornecedores de leite:

$I V$ - refrigeração e estocagem do leite;

VI- higiene de superfícies, equipamentos e instalações;

IX-manejo de ordenha e pós-ordenha;

$X$ - adequação das instalações, equipamentos e utensílios para a produção de leite;

XVI- adoção de práticas de manejo racional e bem-estar animal.

Após os apontamentos das avarias foram solicitadas melhorias na propriedade e uma nova visita ocorreu no mês de janeiro de 2021, sendo verificados os mesmos pontos descritos anteriormente. Na ocasião, ocorreu também a coleta de três amostras (triplicata) para a análise de CPP na Rede Brasileira de Laboratórios de Controle de Qualidade de Leite (RBQL) (Unianálises, Lajeado-RS), de acordo com metodologia oficial da IN 77 (BRASIL, 2018), obtendo média \pm desvio padrão. Também foi verificada a temperatura do leite no tanque de 
expansão e realizada a análise do alizarol $78 \% \mathrm{v} / \mathrm{v}$ em cada propriedade. As amostras foram

devidamente codificadas a fim de manter a integridade dos produtores (1-27).

\section{RESULTADOS E DISCUSSÃO}

Na Tabela 2 podemos verificar os resultados da análise de CPP, da aferição da temperatura do leite cru refrigerado e da análise do alizarol de cada propriedade na primeira e na segunda visita Constatou-se que as 27 propriedades na primeira visita estavam inconformes quanto à análise de CPP. Após a segunda visita, 5 propriedades (18,51\%), ainda estavam com os seus resultados acima do que preconiza a legislação $\left(\leq 300 \times 10^{3} \mathrm{UFC} / \mathrm{mL}\right)$, entretanto, houve uma grande melhora nos demais resultados dos produtores, sendo que o fator apontado como determinante para esta melhoria nos resultados foram as adequações das propriedades quanto aos itens das BPA inconformes na primeira visita. 
Tabela 2. Valores para análise de CPP, aferição da temperatura e análise de alizarol da primeira e segunda visita às propriedades do experimento.

\begin{tabular}{|c|c|c|c|c|c|c|}
\hline \multirow{2}{*}{ Propriedade } & \multicolumn{2}{|c|}{$\mathrm{CPP}\left(\mathrm{x} 10^{3}\right)$} & \multicolumn{2}{|c|}{ Temperatura $\left({ }^{\circ} \mathrm{C}\right)$} & \multicolumn{2}{|c|}{ Alizarol (v/v) } \\
\hline & $1^{\circ}$ visita & $2^{\circ}$ visita & $1^{\circ}$ visita & $2^{\circ}$ visita & $1^{\circ}$ visita & $2^{\circ}$ visita \\
\hline 1 & 1871 & 80 & 4,2 & 3,5 & 78 & 78 \\
\hline 2 & 2485 & 155 & 4,6 & 3 & 78 & 78 \\
\hline 3 & 8467 & 126 & 4,2 & 4 & 78 & 78 \\
\hline 4 & 2509 & 243 & 4 & 4 & 78 & 78 \\
\hline 5 & 325 & 215 & 3,9 & 3,8 & 78 & 78 \\
\hline 6 & 694 & 56 & 3,5 & 3,8 & 78 & 78 \\
\hline 7 & 520 & 61 & 3,4 & 3,6 & 78 & 78 \\
\hline 8 & 853 & 215 & 3 & 3,4 & 78 & 78 \\
\hline 9 & 305 & 92 & 2,5 & 3 & 78 & 78 \\
\hline 10 & 443 & 206 & 4 & 4 & 78 & 78 \\
\hline 11 & 301 & 164 & 4 & 4,2 & 78 & 78 \\
\hline 12 & 350 & 290 & 3,8 & 3,8 & 78 & 78 \\
\hline 13 & 380 & 120 & 3,9 & 4,1 & 78 & 78 \\
\hline 14 & 728 & 80 & 3,8 & 3,6 & 78 & 78 \\
\hline 15 & 4251 & 1250 & 4 & 4 & 78 & 78 \\
\hline 16 & 985 & 820 & 4,2 & 4 & 78 & 78 \\
\hline 17 & 1825 & 1350 & 4,2 & 4 & 78 & 78 \\
\hline 18 & 1325 & 500 & 4 & 3,7 & 78 & 78 \\
\hline 19 & 405 & 90 & 3,8 & 3,8 & 78 & 78 \\
\hline 20 & 920 & 85 & 3,5 & 3,8 & 78 & 78 \\
\hline 21 & 304 & 8 & 3,2 & 3,6 & 78 & 78 \\
\hline 22 & 411 & 105 & 3,9 & 2 & 78 & 78 \\
\hline 23 & 589 & 97 & 3,5 & 2,2 & 78 & 78 \\
\hline 24 & 2191 & 102 & 4,2 & 2,7 & 78 & 78 \\
\hline 25 & 1436 & 85 & 4 & 3 & 78 & 78 \\
\hline 26 & 626 & 190 & 4 & 3,2 & 78 & 78 \\
\hline 27 & 7149 & 390 & 3,7 & 3,5 & 78 & 78 \\
\hline Padrão: & Máx. 300 & $\mathrm{UFC} / \mathrm{mL}$ & $\overline{\text { Má }}$ & ${ }^{\circ} \mathrm{C}$ & Estável & $72 \% \mathrm{v}$ \\
\hline
\end{tabular}

$*$ Os valores em negrito e sombreados apresentam as análises inconformes quanto à legislação vigente. Fonte: Autores (2021).

No estudo realizado por Junior et al. (2013) com o objetivo de avaliar parâmetros microbiológicos e físico-químicos do leite cru refrigerado produzido em 99 propriedades leiteiras da região de Ivaiporã-PR, foram observadas que 54,08\% das amostras para CPP estavam acima do padrão vigente tendo a sua média de 3,63 x $10^{6} \mathrm{UFC} / \mathrm{mL}$ no experimento. Os autores explanaram que estes desvios estão relacionados à falta de higiene na ordenha, assim como Taffarel et al. (2015) relataram que uma alta contagem de CPP pode estar relacionada à falta de higiene durante a ordenha e também a falha no resfriamento do leite, como sendo um 
dos pontos chaves para manter o padrão microbiológico após a ordenha.

Ströher et al. (2020) selecionaram quinze propriedades do Vale do Taquari no ano de 2020, onde as médias trimestrais de CPP do leite estivessem acima do padrão estipulado pela legislação (BRASIL, 2018). Na ocasião foram realizadas duas visitas às propriedades, na primeira foram apontadas as inconformidades em atendimento ao PFQFL (BRASIL, 2018) e proposto melhorias. Já a segunda visita ocorreu passados vinte dias da primeira visita, para a verificação das adequações realizadas em cada propriedade. As duas visitas foram realizadas através de inspeção visual, com a aplicação de checklist. Na ocasião também foram acompanhadas as rotinas das propriedades sendo seguida uma ordenha do começo ao fim e analisadas todas as rotinas praticadas durante período de um turno de trabalho na propriedade. Os autores concluiram que houve uma grande ascenção de adoção das BPAs nas propriedades estudadas após a segunda visita e o aumento significativo na qualidade microbiológica do leite cru refrigerado através das três médias geométricas realizadas posterioemente à segunda visita.

Do contrário, Arcuri et al. (2006) identificaram que os resultados dentro do padrão da legislação de CPP estavam relacionados a correta higiene do equipamento de ordenha e resfriador, sendo utilizado para os procedimentos de limpeza os três produtos recomendados, como detergente alcalino, detergente ácido e o sanitizante. Os mesmos autores observaram que os valores elevados tinham relação com a utilização de apenas dois destes produtos recomendados ou apenas um destes produtos ou nenhum deles.

Conforme estudo desempenhado por Belli et al. (2017), foi verificado que nos sistemas manual e mecanizado com balde ao pé não apresentaram diferença em relação aos valores obtidos para CPP, mas que o sistema canalizado obteve um valor menor em comparação com estes dois sistemas.

Quanto à verificação da temperatura do leite (item IV), na primeira visita, em 6 propriedades $(22,2 \%)$, o leite estava com a sua temperatura superior com o que preconiza a legislação brasileira $\left(\leq 4,0{ }^{\circ} \mathrm{C}\right)$ (BRASIL, 2018). Na ocasião pediu-se que estas propriedades inconformes solicitassem a visita de um técnico especializado para a aferição da temperatura do leite e/ou os ajustes no resfriador. Já na segunda visita, apenas 2 propriedades $(7,40 \%)$, apresentavam inconformidades na temperatura de armazenamento e de coleta do leite, porém esperou-se alguns minutos para que a temperatura diminuisse $\left(\leq 4,0^{\circ} \mathrm{C}\right)$, para a realização da coleta do leite. O resfriamento do leite sendo eficaz desfavorece o aumento de bactérias mesófilas e psicotróficas no leite.

A área de armazenamento do leite deve ser limpa e sem acúmulo de lixo e deve possuir um local apropriado para a lavagem e secagem das mãos e ser de fácil limpeza. O local do 
resfriamento do leite, deve possuir o seu acesso livre, sem obstruções, sendo que à área de coleta

do leite deve ser diferente que a área de passagem dos animais e deve ser livre de barro e outros contaminantes (BRASIL, 2019).

O único teste de qualidade que o transportador possui para a realização na propriedade rural, antes da coleta do leite é o do alizarol, que sobrepõe o teste da acidez do leite; um leite com a acidez elevada, resulta na degradação da proteína do leite e, consequentemente, resulta na instabilidade do alizarol. A análise da estabilidade ao alizarol, deve estar estável na concentração mínima de 72\% v/v (Brasil, 2018).

Todos os resultados do teste de alizarol ( $1^{\mathrm{o}}$ e $2^{\mathrm{o}}$ visita), apresentaram conformidade quanto à legislação brasileira (que deve ser estável ao alizarol 72\% v/v), conforme a Tabela 2.

A verificação dos itens das BPA das propriedades está descrita na Tabela 3. Quanto ao item VI (higiene de superfícies, equipamentos e instalações), podemos observar que em 7 propriedades $(25,92 \%)$ houve inconformidades, sendo que na maioria delas as instalações estavam com sujidades, alguns equipamentos como a ordenhadeira e as tubulações do leite e as mangueiras também não apresentavam boas condições de uso. 
Tabela 3. Verificação do atendimento das BPA na primeira e segunda visita aos produtores do experimento

quanto aos itens VI, IX, X e XVI das boas práticas agropecuárias*.

\begin{tabular}{|c|c|c|c|c|c|c|c|c|}
\hline \multirow{2}{*}{ Propriedade } & \multicolumn{4}{|c|}{$1^{\circ}$ visita } & \multicolumn{4}{|c|}{$2^{\circ}$ visita } \\
\hline & VI & IX & $\mathrm{X}$ & XVI & VI & IX & $X$ & XVI \\
\hline 1 & $\mathrm{C}$ & $\mathrm{C}$ & $\mathrm{C}$ & $\mathrm{C}$ & $\mathrm{C}$ & $\mathrm{C}$ & $\mathrm{C}$ & $\mathrm{C}$ \\
\hline 2 & $\mathrm{C}$ & $\mathrm{C}$ & $\mathrm{C}$ & $\mathrm{C}$ & $\mathrm{C}$ & $\mathrm{C}$ & $\mathrm{C}$ & $\mathrm{C}$ \\
\hline 3 & $\mathrm{C}$ & $\mathrm{C}$ & $\mathrm{C}$ & $\mathrm{C}$ & $\mathrm{C}$ & $\mathrm{C}$ & $\mathrm{C}$ & $\mathrm{C}$ \\
\hline 4 & NC & NC & $\mathrm{NC}$ & $\mathrm{C}$ & $\mathrm{C}$ & $\mathrm{C}$ & $\mathrm{C}$ & $\mathrm{C}$ \\
\hline 5 & NC & NC & $\mathrm{NC}$ & $\mathrm{C}$ & $\mathrm{C}$ & $\mathrm{C}$ & $\mathrm{C}$ & $\mathrm{C}$ \\
\hline 6 & $\mathrm{C}$ & NC & $\mathrm{NC}$ & $\mathrm{C}$ & $\mathrm{C}$ & $\mathrm{C}$ & $\mathrm{C}$ & $\mathrm{C}$ \\
\hline 7 & $\mathrm{C}$ & $\mathrm{C}$ & $\mathrm{NC}$ & $\mathrm{C}$ & $\mathrm{C}$ & $\mathrm{C}$ & $\mathrm{C}$ & $\mathrm{C}$ \\
\hline 8 & $\mathrm{C}$ & $\mathrm{C}$ & $\mathrm{C}$ & $\mathrm{C}$ & $\mathrm{C}$ & $\mathrm{C}$ & $\mathrm{C}$ & $\mathrm{C}$ \\
\hline 9 & NC & $\mathrm{NC}$ & $\mathrm{NC}$ & $\mathrm{C}$ & $\mathrm{C}$ & $\mathrm{C}$ & $\mathrm{C}$ & $\mathrm{C}$ \\
\hline 10 & $\mathrm{C}$ & $\mathrm{C}$ & $\mathrm{C}$ & $\mathrm{C}$ & $\mathrm{C}$ & $\mathrm{C}$ & $\mathrm{C}$ & $\mathrm{C}$ \\
\hline 11 & $\mathrm{NC}$ & $\mathrm{NC}$ & $\mathrm{NC}$ & $\mathrm{C}$ & $\mathrm{C}$ & $\mathrm{C}$ & $\mathrm{C}$ & $\mathrm{C}$ \\
\hline 12 & $\mathrm{NC}$ & NC & $\mathrm{NC}$ & $\mathrm{C}$ & $\mathrm{C}$ & $\mathrm{C}$ & $\mathrm{C}$ & $\mathrm{C}$ \\
\hline 13 & $\mathrm{NC}$ & $\mathrm{NC}$ & $\mathrm{NC}$ & $\mathrm{C}$ & $\mathrm{C}$ & $\mathrm{C}$ & $\mathrm{C}$ & $\mathrm{C}$ \\
\hline 14 & $\mathrm{C}$ & $\mathrm{C}$ & $\mathrm{C}$ & $\mathrm{C}$ & $\mathrm{C}$ & $\mathrm{C}$ & $\mathrm{C}$ & $\mathrm{C}$ \\
\hline 15 & $\mathrm{C}$ & $\mathrm{C}$ & $\mathrm{C}$ & $\mathrm{C}$ & $\mathrm{C}$ & $\mathrm{C}$ & $\mathrm{C}$ & $\mathrm{C}$ \\
\hline 16 & $\mathrm{C}$ & $\mathrm{C}$ & $\mathrm{C}$ & $\mathrm{C}$ & $\mathrm{C}$ & $\mathrm{C}$ & $\mathrm{C}$ & $\mathrm{C}$ \\
\hline 17 & $\mathrm{C}$ & $\mathrm{C}$ & $\mathrm{C}$ & $\mathrm{C}$ & $\mathrm{C}$ & $\mathrm{C}$ & $\mathrm{C}$ & $\mathrm{C}$ \\
\hline 18 & $\mathrm{C}$ & $\mathrm{C}$ & $\mathrm{C}$ & $\mathrm{C}$ & $\mathrm{C}$ & $\mathrm{C}$ & $\mathrm{C}$ & $\mathrm{C}$ \\
\hline 19 & $\mathrm{C}$ & NC & $\mathrm{NC}$ & $\mathrm{C}$ & $\mathrm{C}$ & $\mathrm{C}$ & $\mathrm{C}$ & C \\
\hline 20 & C & NC & $\mathrm{NC}$ & C & $\mathrm{C}$ & $\mathrm{C}$ & $\mathrm{C}$ & $\mathrm{C}$ \\
\hline 21 & $\mathrm{C}$ & $\mathrm{C}$ & $\mathrm{C}$ & $\mathrm{C}$ & $\mathrm{C}$ & $\mathrm{C}$ & $\mathrm{C}$ & $\mathrm{C}$ \\
\hline 22 & $\mathrm{C}$ & $\mathrm{C}$ & C & C & $\mathrm{C}$ & $\mathrm{C}$ & $\mathrm{C}$ & $\mathrm{C}$ \\
\hline 23 & NC & NC & $\mathrm{NC}$ & $\mathrm{C}$ & $\mathrm{C}$ & $\mathrm{C}$ & $\mathrm{C}$ & $\mathrm{C}$ \\
\hline 24 & $\mathrm{C}$ & $\mathrm{C}$ & $\mathrm{C}$ & $\mathrm{C}$ & $\mathrm{C}$ & $\mathrm{C}$ & $\mathrm{C}$ & $\mathrm{C}$ \\
\hline 25 & $\mathrm{C}$ & $\mathrm{C}$ & $\mathrm{C}$ & $\mathrm{C}$ & $\mathrm{C}$ & $\mathrm{C}$ & $\mathrm{C}$ & $\mathrm{C}$ \\
\hline 26 & $\mathrm{C}$ & $\mathrm{C}$ & $\mathrm{C}$ & C & $\mathrm{C}$ & $\mathrm{C}$ & $\mathrm{C}$ & $\mathrm{C}$ \\
\hline 27 & C & $\mathrm{C}$ & C & C & $\mathrm{C}$ & $\mathrm{C}$ & C & $\mathrm{C}$ \\
\hline
\end{tabular}

*IV-refrigeração e estocagem do leite; VI- higiene de superfícies, equipamentos e instalações; IX-manejo de ordenha e pós-ordenha; X-adequação das instalações, equipamentos e utensílios para a produção de leite e XVIadoção de práticas de manejo racional e bem-estar animal. *Os valores em negrito e sombreados apresentam as análises inconformes à legislação.

Fonte: Autores (2021).

No item IV (manejo de ordenha e pós-ordenha), foram observados os seguintes itens: se a ordenha era mecânica ou manual (todas as propriedades possuiam ordenhadeira mecânica); se as propriedades possuiam ordenhadeira canalizada (e quantos conjuntos): as propriedades possuiam ordenha canalizada e balde ao pé; se o local da ordenha era mantido limpo e organizado: em 7 propriedades $(25,92 \%)$, havia a presença de sujidades nos equipamentos de ordenha e nas tubulações do leite. Também foi verificado se haviam animais em fase colostral: 
foi constatado, porém este leite era descartado pelos produtores e não foram misturados ao leite entregue ao laticínio. Foi questionado se os produtores realizavam o teste da caneca de fundo preto e o teste de CMT, para a identifição de mastite: em 4 propriedades $(14,81 \%)$, estes testes não eram realizados. Também foi observado se após a ordenha era fornecido alimentos aos animais pós-ordenhados com a finalidade de ficarem em pé, pois assim, a tempo do úbere se fechar evitando-se a contaminação por micro-organismos, quando os animais se deitarem. A água fornecida aos animais e para a higienização da ordenha e dos equipamentos, possuia aparência limpa e de boa qualidade, assim como preconiza a legislação (BRASIL, 2018). E por último, verificou-se se havia a presença de equipamento aquecedor, para aquecer a água com o objetivo de fazer a correta higiene da ordenha e dos materiais, pois cada produto químico utilizado possui uma temperatura ideal de ação, conforme já falado anteriormente.

Segundo Brasil (2019), os produtores rurais devem ser qualificados quanto às práticas que garantam uma rotina de ordenha higiênica, não lesione e evite a transmissão de doenças entre os animais e que não introduza contaminantes no leite como é o caso dos antibióticos. Os procedimentos de limpeza e sanitização devem estar descritos em manuais dispostos nas propriedades rurais sendo que os trabalhadores devem possuir treinamentos para tal finalidade.

No estudo de Reche et al. (2015), dos produtores avaliados, 94,7\% disponibilizava de água com aquecimento na sala de ordenha, sendo que apenas $22,2 \%$ realizavam o controle da temperatura da água que era utilizada e 78,9\% faziam uso dos detergentes como o alcalino clorado e o ácido durante o processo de higienização do resfriador e do equipamento de ordenha, onde os resultados indicaram que as boas práticas de manejo têm impacto direto sobre a contagem inicial de micro-organismos.

Verificou-se que em 4 propriedades não havia a realização da limpeza da ordenha e dos equipamentos com nenhum produto recomendado para a sua higienização e constatou-se que somente era utilizado o detergente de cozinha tradicional, sendo que ele não é recomendado, pois além de deixar cheiro nos equipamentos, não possui eficiência comprovada para tais fins.

Também verificou-se que em 8 propriedades (29,62\%), não havia tempo e temperatura recomendada para a utilização dos detergentes (ácido, alcalino e alcalino clorado) sendo adicionados quantidades de produto aleatória, conforme predisposição do ordenhador.

O estudo realizado por Taffarel et al. (2012) com produtores sobre a temperatura recomendada da água em detergente alcalino, mostrou que 44,77\% utilizavam em temperatura adequada sendo esta entre 70 a $80^{\circ} \mathrm{C}$. Já $45,93 \%$ fazia uso de água na temperatura inferior, $5,81 \%$ não souberam informar ou não responderam e o restante $3,49 \%$ informaram que a temperatura da água era superior ao que é recomendada. Fica evidente que os produtores fazem 
uso de detergentes para o processo de limpeza, porém o uso de água fria utilizada pela maioria deles compromete a sua eficiência.

Matsubara et al. (2011), após aplicarem diferentes práticas de ordenha como: desprezo dos três primeiros jatos, imersão dos tetos em solução clorada, higienização inversão dos latões e baldes para eliminação da água residual, demonstraram que a implantação de boas práticas de ordenha podem ser suficientes para adequar o leite produzido aos parâmetros estabelecidos pela legislação. Vallin et al. (2009) concluíram que a adoção de boas práticas são simples de serem implementadas na rotina de ordenha, e contribuem para a melhoria da qualidade do leite em quaisquer condições.

Foi obervado que em 7 propriedades $(14,81 \%)$ (Tabela 3), as teteiras e mangueiras já estavam desgastadas e seu uso já havia ultrapasado o tempo recomendado. No caso das mangueiras que possuem contato direto com o leite, é necessário que sejam realizadas as trocas a cada seis meses e em relação a mangueira utilizada para vácuo, a troca deve ser feita uma vez ao ano (GENTILINI; SANTOS, 2019).

As teteiras que possuem contato direto com o leite também devem ser trocadas periodicamente, pois quando se encontram gastas e envelhecidas prejudicam a massagem correta dos tetos, desencadeando problemas como congestão e edema, contribuindo assim para o aparecimento de lesões. Portanto, a troca das teteiras de borracha deve ser efetuada conforme o número de ordenha realizado, sendo recomendada a troca destas a cada 2.500 ordenhas ou sempre que forem observados sinais de desgaste ou diminuição na eficiência da mesma (GENTILINI; SANTOS, 2019). A superfície das teteiras deve ter aspecto liso e permanecer alinhada dentro do copo da teteira, evitando a torção das mesmas (GENTILINI; SANTOS, 2019).

Em seu estudo Coentrão et al. (2008) detectaram alguns pontos que são considerados fatores de risco em relação ao equipamento como, por exemplo, nos itens de borracha foram observados presença de rachaduras ou fissuras, teteiras em estado de conservação ruim, além de falhas relacionadas a limpeza dos pulsadores.

O estudo realizado por Silva et al. (2011) identificou que a higienização das teteiras era um processo realizado apenas com uso de água ao final de cada ordenha. O mesmo autor verificou que antes do início da ordenha o grau de contaminação nas mesmas era considerado alto, sendo observado a redução da quantidade de micro-organismos presentes em sua superfície ao término da ordenha, possivelmente por ter sido transferido ao leite essa contaminação durante o processo de ordenha.

Também foi observado que em 4 propriedades $(14,81 \%)$, não havia a utilização do pré 
e pós-dipping. Brito et al., (2000) notaram que a lavagem dos tetos com água seguida de secagem com papel toalha individual reduziu o número de patógenos na superfície dos tetos, mas a redução é muito maior quando se emprega o uso de pré-dipping.

Quanto ao item XVI (adoção de práticas de manejo racional e de bem-estar animal), todo os produtores apresentaram conformidade, sendo que as técnicas de manejo, as instalações das propriedades garantem o bem-estar dos animais, entretanto, não há registros de treinamentos realizados visando o bem-estar animal na propriedade. Segundo Brasil (2019), o produtor deve adotar práticas que mantenham os animais livres de fome e sede, livres de desconforto, livres de dor, lesões ou doenças, enfim, devem expressar seus comportamentos normais e livres de medo e aflição.

Assim, como este trabalho, Arcuri et al., (2006) revelaram que após orientações, recomendações e ações técnicas, os resultados obtidos pelo produtor para contagem padrão em placas foram menores que a primeira visita na propriedade. Solicitou-se também que fossem utilizados detergentes (alcalino e ácido) e também sanitizante.

Podemos observar (Tabela 3), que após a segunda visita, todos os produtores se enquadraram aos itens avaliados, sendo que este resultado condiz com a diminuição dos resultados das contagens de CPP do leite também na segunda visita às propriedades.

Ströher et al., (2020), relatam que o governo brasileiro deve estimular os pequenos produtores a se enquadrarem no que preconiza as instruções normativas para a produção do leite cru refrigerado, destacando-se a importância da concientização dos produtores através de elaboração de material informativo, capacitações, visitas de orientação para in loco.

\section{CONCLUSÕES}

Podemos constatar que na primeira visita às propriedades houve não conformidades nos itens de $n^{\circ}$ VI $(25,92 \%)$, IX (37,03\%) item X (40,74\%) e a completa conformidade quanto ao teste de alizarol (item XVI). Já na segunda visita observou-se que seis propriedades apresentaram CPP acima da legislação. Seis propriedades na primeira visita estavam com a temperatura do leite acima de $4,0^{\circ} \mathrm{C}$ e na segunda visita, duas propriedades ainda não estavam adequadas.

Os equipamentos de ordenha merecem atenção especial por parte do produtor, pois a limpeza ineficiente pode ser a causa da contaminação do leite. Foi constatado que o uso de detergentes como o alcalino clorado, o detergente ácido, alcalino e o neutro, além de práticas como o teste de CMT e o pré e pós-dipping são fundamentais na melhoria da qualidade do leite 
produzido.

No presente estudo foi possível verificar que os ajustes realizados nas propriedades rurais visitadas contribuiram para aumentar a qualidade do leite, diminuindo as contagens de CPP. Desta forma é possível observar que a assistência técnica realizada na propriedade foi importante na busca de melhorias, garantindo assim a qualidade do leite cru refrigerado.

\section{REFERÊNCIAS}

ARCURI, E.F. Qualidade microbiológica do leite refrigerado nas fazendas. Arquivo Brasileiro de Medicina Veterinária e Zootecnia, [S.L.], v. 58, n. 3, p. 440-446, jun. 2006. FapUNIFESP (SciELO). http://dx.doi.org/10.1590/s0102 09352006000300024.

BOAS PRÁTICAS AGROPECUÁRIAS. Sindileite. Cir Gráfica e Editora Ltda $3^{\mathrm{a}}$ edição. 2020.

BOOR KJ, WIEDMANN M, MURPHY S, ALCAINE S. A 100-Year Review: Microbiology and safety of milk handling. (1525-3198 (Electronic)) 2017.

BRASIL. Ministério da Agricultura Pecuária e Abastecimento. (2018) Instrução Normativa ${ }^{\circ}$ 77. Brasília, DF: MAPA. Diário Oficial da República Federativa do Brasil. Disponível em: https://www.gov.br/agricultura/pt-br/. Acesso em 02 abr. 2021.

BRASIL. Ministério da Agricultura Pecuária e Abastecimento. (2018) Instrução Normativa no 76. Brasília, DF: MAPA. Diário Oficial da República Federativa do Brasil. Disponível em: https://www.gov.br/agricultura/pt-br/. Acesso em 02 abr. 2021.

BRASIL. Ministério da Agricultura Pecuária e Abastecimento. Decreto $\mathbf{N}^{\circ}$ 9.013, de 29 de março de 2017. Regulamento da Inspeção Industrial e Sanitária de Produtos de Origem Animal- Riispoa. Brasília: Diário Oficial. 2017; Edição 62, Seção 1, Página 3.

BRASIL. Ministério da Agricultura, Pecuária e Abastecimento. Regulamento de Inspeção Industrial e Sanitária de Produtos de Origem Animal - RIISPOA. Diário Oficial da República Federativa do Brasil, Brasília, DF, 27 mar. 2017.

BUENO V.F.F, MESQUITA A.J.D, OLIVEIRA A.N, NICOLAU E.S, NEVES R.B.S. Contagem bacteriana total do leite: relação com a composição centesimal e período do ano no Estado de Goiás. 2008.

CARVALHO, T. S; SILVA, M. A. P.; BRASIL, R. B.; LEÃO, K. M.; SILVA, M. R; MORAIS, L. A. Influência da contagem de células somáticas na composição química do leite refrigerado da Região Sudoeste de Goiás. Revista Instituto Laticínio. Cândido Tostes, Juiz de Fora, v. 70, n. 4, p. 200-205, 2015.

CAVALCANTI, E.R.C.; CAVALCANTI, M.A.R.; SOUZA, W.J.; ARAUJO, D.G. Avaliação microbiológica em ordenhadeira mecânica antes e após a adoção de procedimento orientado de higienização. Revista Brasileira de Ciência Veterinária, v.17, n.1, p.3-6, 2010. 
COENTRÃO, C.M. et al. Fatores de risco para mastite subclínica em vacas leiteiras. Arquivo Brasileiro de Medicina Veterinária e Zootecnia, [S.L.], v. 60, n. 2, p. 283-288, abr. 2008. FapUNIFESP (SciELO). http://dx.doi.org/10.1590/s0102-09352008000200001.

$\begin{array}{lllllll}\text { CONAB, } & \text { aceso } & \text { em } & 20 & \text { de }\end{array}$ https://www.conab.gov.br/institucional/publicacoes/compendio-de-estudos-da-conab.

DIAS J.A, ANTES FG. Qualidade físico-química, higiênico-sanitária e composicional do leite cru: indicadores e aplicações práticas da Instrução Normativa 62. In: Rondônia E, editor. Base de Dados da Pesquisa Agropecuária (BDPA)2014.

ECKSTEIN, I. I. et al. Contagem Bacteriana Total e Contagem de Células Somáticas do leite cru em diferentes tipos e tempos de resfriamento. In: CONGRESSO BRASILEIRO DE QUALIDADE DO LEITE. 4. 2010. Florianópolis. Anais... Florianópolis: CAV, 2010.

GENTILINI, Marianna Barbosa; SANTOS, Marcos Veiga dos. Sistemas de ordenha. In: SANTOS, Marcos Veiga dos; FONSECA, Luis Fernando Laranja da. Controle da mastite e qualidade do leite: desafios e soluções. Pirassununga: Edição dos Autores, 2019. p. 196-221.

GRACINDO, A, P. A. C.; PEREIRA, G. F. (2009). Produzindo leite de alta qualidade. Recuperado de http://www.emparn.rn.gov.br/contentproducao/aplicacao/emparn/arquivos/pdf/

HAYES MC, RALYEA RD, MURPHY SC, CAREY NR, SCARLETT JM, BOOR KJ. Identification and characterization of elevated microbial counts in bulk tank raw milk. J Dairy Sci. 2001;84(1):292-8.https://www.scielo.br/. Acesso em 02 abr. 2021.

JAYARAO BM, DONALDSON SC, STRALEY BA, SAWANT AA, HEGDE NV, BROWN JL. A survey of foodborne pathogens in bulk tank milk and raw milk consumption among farm families in Pennsylvania. J Dairy Sci. 2006;89(7):2451-8.

JÚNIOR, J.C.R; BELOTI, V.; CAVALETTI, L.; DA SILVA, C.; TAMANINI, R. Avaliação da qualidade microbiológica e físico-química do leite cru refrigerado produzido na região de Ivaiporã, Paraná. Rev. Inst. Laticínios Cândido Tostes, Juiz de Fora, v. 68, n. 392, p. 5-11, mai.jun., 2013. Disponível em:< https://www.revistadoilct.com.br/rilct/article/view/23/27> Acesso em: 30 mar 2021.

KIM, S.G; KIM, E.H; LAFFERTY, C.J; DUBOVI, E. Coxiella burnetti in bulk tank milk samples, United States. Emerg Infect Dis. 2005;11(4):619-21.

KUHN E, MEUNIER-GODDIK L, WAITE-CUSIC JG. Effect of leaving milk trucks empty and idle for $6 \mathbf{h}$ between raw milk loads. J. Dairy Sci. 2018;101(2):1767-76.

LANGE, M. J.; ZAMBOM, M. A.; POZZA, M. S. S.; SIMÕES, G. H.; FERNANDES, T.; TININI, R. C. R.; FORNARI, J.; ANSCHAU, F. A. Tipologia de manejo de ordenha: análise de fatores de risco para a mastite subclínica. Pesq. Vet. Bras., Rio de Janeiro, v. 37, n. 11, p. 1205-1212, nov. 2017. Disponível em: Acesso em 02 abr. 2021.

LANGONI, H. et al. Aspectos microbiológicos e de qualidade do leite bovino. Pesquisa Veterinária Brasileira, v. 31, n. 12, p. 1059- 1065, 2011.

LIMA, Bruna Lorrayne; COELHO, Karyne Oliveira; BUENO, Cláudia Peixoto; NEVES, 
Rodrigo Balduino Soares. Contagem celular somática nos grandes constituintes do leite. Revista Medicina Veterinária e Zootecnia. v.10, n.8, p.604- 607, 2016.

LIMA, M. C. G. et al. Contagem de células somáticas e análises físico-químicas e MESQUITA A.A, BORGES J, PINTO SM, LUGLI FDF, CASTRO ACDO, OLIVEIRA MRD, et al. Contagem bacteriana total e contagem de células somáticas como indicadores de perdas de produção de leite. Pubvet. 2018;12(6):1-8.

MILANI, M. P. (2011). Qualidade do leite em diferentes sistemas de produção, anos e estações climáticas no noroeste do Rio Grande do Sul. Dissertação (Mestrado) - Curso de Ciência e Tecnologia de Alimentos, Universidade de Santa Maria.

MILLOGO, V. et al. Raw milk hygiene at farms, processing units and local markets in Burkina Faso. Food Control, v. 21, n. 7, p. 1070-1074, 2010.

MUEHLHERR JE, ZWEIFEL C, CORTI S, BLANCO JE, STEPHAN R. Microbiological quality of raw goat's and ewe's bulk-tank milk in Switzerland. J Dairy Sci.. 2003;86(12):3849-56.

MURPHY, S.C, MARTIN, N.H, BARBANO, D.M, WIEDMANN, M. Influence of raw milk quality on processed dairy products: How do raw milk quality test results relate to product quality and yield. J Dairy Sci. 2016;99(12):10128-49.

O'CONNELL A, RUEGG PL, JORDAN K, O'BRIEN B, GLEESON D. The effect of storage temperature and duration on the microbial quality of bulk tank milk. J. Dairy Sci. 2016;99(5):3367-74.

OLIVEIRA, C. A. F.; FONSECA, L. F. L; GERMANO, P. M. L. Aspectos relacionados à produção, que influenciam a qualidade do leite. Higiene Alimentar. São Paulo, SP, 2005.

OLIVEIRA, R. R. et al. Determinação do caseinomacropeptídeo em leite UAT por

PAIXÃO, M. G; DOMINGO, E.C; GAJO, A.A; TORRES, L.M; ABREU, L.M; PINTO, S.M. Carretagem de Leite a Granel: Um estudo de Caso. Rev. Inst. Latic. "Cândido Tostes", Set/Out,n 382, 66: 42-47, 2011.

PONCHIO, L. A.; CONTE, R .N.B. Lucro e produtividade no RS andam lado a lado. Boletim do Leite, USP/ESALQ, v.10, n.112, jul. 2003.

PORCELLATO D, SKEIE SB. Bacterial dynamics and functional analysis of microbial metagenomes during ripening of Dutch-type cheese. Int Dairy J. 2016;61(C):182-8. 14. Santos M. Influência da qualidade do leite na manufatura e vida de pratel.

ROSA, L. S.; QUEIROZ, M. I. Avaliação da qualidade do leite cru e resfriado mediante a aplicação de princípios do APPCC. Ciência e Tecnologia de Alimentos, v. 27, n. 2, p. 422- 430, 2007.

SAMPAIO, V.S.C; SOUZA, F.N; SARAIVA, C.J.C; SANTOS, R.P; LEITE, M.O; RESENDE, G.M; GONÇALVEZ, N.C; DIONIZIO, F.L; CERQUEIRA, M.M.O.P. Influência de diferentes tipos de micro-organismos na contagem bacteriana total por citometria de fluxo do leite cru refrigerado. Arq. Bras. Med. Vet. Zootec., v.67, n.2, p.607-612, 2015. Disponível em:< 
https://www.scielo.br/pdf/abmvz/v67n2/0102-0935-abmvz-67-02-00607.pdf>. Acesso em 30 $\operatorname{mar} 2021$.

SANTOS MV, FONSECA LFL. Estratégias para controle de mastite e melhoria da qualidade do leite, 2007.

SANTOS P.A, SILVA M.A.P, SOUZA CM, ISEPON JS, Oliveira NA, Nicolau ES. Efeito do tempo e da temperatura de refrigeração no desenvolvimento de microrganismos psicrotróficos em leite cru refrigerado coletado na macrorregião de Goiânia, GO. Ciênc. anim. bras, 2009. 10(4), 1237-1245

SANTOS, M. Influência da qualidade do leite na manufatura e vida de prateleira dos produtos lácteos: papel das células somáticas. Brito, JRF, Portugual, JAB (Org). 2003;1:13949.

SANTOS. L. Prestação de serviços em equipamentos de ordenha e análise do manejo de ordenha em três fazendas leiteiras. Relatório de Estágio - Graduação de Zootecnia Universidade Federal Rural de Pernambuco/PE, 2019.

SIQUEIRA, K. B.; CARNEIRO, A. V. Principais indicadores leite e derivados: boletim eletrônico mensal. Juiz de Fora: Embrapa Gado de Leite, v. 5, n.39, 13 fev. 2012.

SKEIE SB, HÅLAND M, THORSEN IM, NARVHUS J, PORCELLATO D. Bulk tank raw milk microbiota differs within and between farms: A moving goalpost challenging quality control. J Dairy Sci. 2019;102(3):1959-71.

SOUZA, A. P.; HONORATO, L. A.; GÓMEZ, C. U.; CARDOSO, C. S.; HOTZEL, M. J. Construção e uso de indicadores para avaliação do manejo da ordenha: uma proposta metodológica participativa. Cienc. Rural, Santa Maria, v. 44, n. 5, p. 911-917, Mai 2014. Disponível em: Acesso em 02 abr. 2021.

STRÖHER, J. A; CAXAMBU, S; VOGEL. J; dos SANTOS JR, L.C.O. Avaliação do leite cru refrigerado de uma agroindústria de laticínios da Serra Gaúcha-RS. Congresso Internacional da Agroindústria. 2020. doi: doi.org/10.31692/ICIAGRO.2020.0284. Disponível em: $\langle$ https://ciagro.institutoidv.org/ciagro/uploads/643.pdf $>$. Acesso em: 30 mar. 2021.

STRÖHER, J. A; dos SANTOS JR, L.C.O; ERHARDT, M.M; FRÖFER, H; CAXAMBU, S. Avaliação dos parâmetros microbiológicos e das boas práticas agropecuárias em propriedades leiteiras do vale do taquari-RS. V Congresso das Ciências Agrárias. 2020. Doi: https://doi.org/10.31692/2526-7701.VCOINTERPDVAgro.0192. Disponível em:< https://cointer.institutoidv.org/smart/2020/pdvagro/uploads/3514.pdf>. Acesso em: 30 mar. 2021.

STRÖHER, J.A; SANT’ANNA, V.; CLASEN, B.E; ERHARDT, M.M; VOGEL, J. Avaliação da conformidade nos parâmetros da instrução normativa número 76 de produtores de leite da Serra Gaúcha-RS. Congresso Brasileiro de segurança alimentar. 2019. Disponívelem:http://schenautomacao.com.br/ssa7/envio/files/trabalho3_11.pdf: Acesso em 30 mar 2021.

TAFFAREL, L.E. et al. Contagem bacteriana total no leite em diferentes sistemas de ordenha e de resfriamento. Arq. Inst. Biol., São Paulo, v.80, n.1, p.7-11, jan./mar., 2013. 
Usina Escola de Laticínios da UFSM. 2013.[TCC]. Santa Maria: Universidade Federal de Santa Maria, 2013.

TONET, R. M.; BANKUTI, F. I.; DAMASCENO, J. C. Interferência dos padrões de qualidade (CCS e CBT) no processamento de leite fluido e derivados. 2020. Disponível em: https://www.milkpoint.com.br/artigos/industria-de-laticinios/a-vulnerabilidade-dospadroesde-qualidade-do-leite-e-a-relacao-entre-a-industria-e-os-produtores-218435/. Acesso em 02 abr. 2021.

TRIBST AAL, FALCADE I, de OLIVEIRA MM. Strategies for raw sheep milk storage in smallholdings: Effect of freezing or long-term refrigerated storage on microbial growth. J Dairy Sci 2019;102(6):4960-71.

TRONCO, V. M.; Manual para inspeção da qualidade do leite, 2.ed. Ed. Da UFSM, Santa Maria, 2003.

VALLIN, V. M. et al; Melhoria da qualidade do leite a partir da implantação de boas práticas de higiene na ordenha em 19 municípios da região central do Paraná. Semina: Ciências Agrárias, Londrina, v. 30, n. 1, p. 181-188, jan. 2009. Disponível em: https://www.bvsvet.org.br/. Acesso em 02 abr. 2021.

VIEIRA, Mary A. C. G. Assistência técnica x qualidade do Leite: Importância das Boas Práticas de Produção na Fazenda paras as Indústrias de Laticínios. Trabalho de Conclusão de Curso (Bacharelado em Zootecnia) - Unidade Acadêmica de Serra Talhada, Universidade Federal Rural de Pernambuco, Serra Talhada, 2019.

WENTZ AG, BERMUDES RF, de MAGALHÃES MARTINS CM, OSMARi MP, RODRIGUES BM, dos SANTOS POZZA MS. Different methods and times of milk conservation: Physical-chemical composition and microbiological quality. Acta Veterinaria Brasilica. 2018;12(3):84-93. 